\title{
Çocuklarda ayak muayenesi
}

\author{
Foot examination in children
}

\author{
Namık Şahin \\ Sağlık Bilimleri Üniversitesi Konya Eğitim ve Araştırma Hastanesi, Ortopedi ve Travmatoloji Kliniği, Konya, Türkiye
}

\begin{abstract}
Çocuklar sıklıkla ayak ile ilgili yakınmalar nedeniyle aileleri tarafından ortopedi muayenesi için getirilirler. Çocuğun yaş grubuna göre ailelerin yakınmaları ve karşılaşılan sorunlar da farklılıklar gösterir. Yenidoğan döneminde ve yürüme öncesi çocuklarda genellikle doğumsal sorunlar başvuru nedenidir. Yürüme döneminden sonra ise ağrılı durumlarla sıkça karşılaşılır. Yine yürüme çağındaki çocuklarda fizyolojik sınırlar içinde olan bazı deformiteler ailelerde fazlaca kaygı nedeni olabilir. Dikkatli alınan bir öykü çoğu zaman olası tanı ile ilgili fazlaca bilgi verebilir. Hastaneye başvuru nedeni dikkatlice dinlenmelidir. Özellikle yenidoğan döneminde "normal” olarak kabul edilen kas-iskelet sistemi özelliklerinin bilinmesi ayağın doğru olarak değerlendirilmesini kolaylaştırır, gereksiz tetkik ve tedavilerin önüne geçer. Çocukta ayak muayenesi genel olarak gözlem, palpasyon ve manipülasyon sırasıyla yapılır. Özellikle travmatik olgularda ağrı yerinin dikkatli olarak tespit edilmesi tanıda oldukça yardımcıdır. Polikliniklerde, yenidoğan döneminde ayak deformiteleri ile nispeten sık karşılaşılır. Bu deformitelerin yaklaşık dörtte üçünü metatarsus adduktus oluşturur. Talipes equinovarus, kalkaneovalgus ve vertikal talus daha az görülen deformitelerdir. Yürüme çağından sonra ise içe basma yakınması ve travma sonucu ortaya çıkan sorunlar sık başvuru nedenleridir.
\end{abstract}

Anahtar sözcükler: çocuk; ayak; öykü; muayene
Children are frequently brought to the orthopedic examination by their parents due to complaints about their foot. According to the child's age group, the complaints of the family and also the problems encountered show differences. Congenital problems are usually the reason for referrals in newborn and pre-gait children. After the walking period, painful conditions are frequently encountered. In addition, some deformities in the physiological limits of toddler may be a cause of concern in their families. A careful story can often give a lot of information about possible diagnosis. The reason for referral to the hospital should be carefully evaluated. Knowing the characteristics of the musculoskeletal system, which is "normal" especially in the newborn period, facilitates accurate evaluation of the foot and avoids unnecessary examinations and treatments. The child's foot examination is generally performed in the order of observation, palpation and manipulation. Especially in cases of traumatic events, it is very helpful to determine carefully the location of the pain. In outpatient clinics, foot deformities are relatively common among newborns. About threequarters of these deformities are metatarsus adductus. Talipes equinovarus, calcaneovalgus and vertical talus are less commonly seen deformities. Especially after the walking age, complaints of intoeing and traumatic problems are frequent reasons for visiting the outpatient clinics.

Key words: child; foot; story; examination

\section{ÇOCUKLARDA AYAK MUAYENESi}

Çocuk yaş grubunda ayak ile ilgili yakınmalar nedeniyle hastaneye başvurma oranları oldukça fazladır. Hastaların çoğunda dikkatli bir öykü, fizik muayene ve basit tetkiklerle tanı koymak mümkün olur. Diğer yandan, çocuklarda başvuru nedenleri incelendikten sonra, tespit edilen sorunların nereye kadar fizyolojik ve hangi aşamadan sonra patolojik olduğunu tespit etmek her zaman kolay olmayabilir. Çocuğun yaş grubuna göre karşılaşılan sorunlar da farklılıklar gösterir. Yenidoğan döneminde ve yürüme öncesi çocuklarda genellikle doğumsal anomaliler başvuru nedenidir. Yürüme döneminden sonra ise ağrılı durumlarla sıkça karşılaşılır. Aktif çocuk yaş grubunda ayak ağrısı, genellikle küçük travma ya da tekrarlayan streslerle ve buna bağlı ortaya çıkan anormal ayak biyomekaniği ile ilgilidir. Büyük çocuklar ağrının yerini tam olarak belirleyebilirken, daha küçük çocuklarda bu durum

- İletişim adresi: Doç. Dr. Namık Şahin, Sağlık Bilimleri Üniversitesi Konya Eğitim ve Araştırma Hastanesi, Hacı Şaban Mah. Yeniyol Cad. No:97. 42090 Meram, Konya Tel: 0332 - 2210000 / 4007 e-posta: sahinnamik@yahoo.com

- Geliștarihi: 17 Kasım $2017 \quad$ Kabul tarihi: 17 Kasım 2017 
topallama ya da basmaktan çekinme şeklinde görülebilir. Bununla birlikte, travmaya dair net bir öykü olmayabilir. Travmayı taklit eden ağrılı hastalıkları da akıldan çıkarmamak gerekir.

\section{Öykü Alma}

Dikkatli alınan bir öykü, olası tanı ile ilgili fazlaca ipuçları verebilir. Ancak, öykünün ve fizik muayenenin özellikle çocuk yaş grubunda her zaman gerçeği yansıtmayabileceğinin unutulmaması gerekir. Öykü alma işleminin iyi bir konuşma tekniği ile sohbet havası içinde yürütülmesi gerekir. Öykü alma sırasında çocuk annesinin kucağında ise, çocuğun rahatlaması için başlangıçta kucakta kalmasına izin verilebilir. Hastaneye başvuru nedeni dikkatlice dinlenmelidir. Muayene süresi içinde gözlenmesi mümkün olmayan bazı durumlar aile tarafindan evde gözlenmiş olabilir. Başvuru nedeni ağrı ise, ağrının özellikleri tam olarak tanımlanmalıdır. Ağrının yeri, karakteri, başlangıcı, süresi, aktivite ya da istirahatle değişip değişmediği, ağrıyı arttıran ve azaltan etkenler sorgulanmalıdır. Travmanın varlığı, akut büyük bir travma ya da tekrarlayan küçük travmalar araştırılmalıdır. Nörolojik ve inflamatuvar bulgular sorgulanmalı, var ise önceki tedavilerin etkisi araştırılmalıdır. Ağrının yerinin tam anlaşılması, öykünün tanıya yardımcı en önemli kısmıdır.

Ayrıca, çocuğun doğum şekli, doğum öncesi ve sonrasında yaşadığı sorunlar, ailedeki bazı hastalıkların varlığı tanı koymada yol gösterici olabilir. Bu nedenle, gebelik ve doğum öyküsü ayrıntılarıyla alınmalıdır.

\section{Fizik Muayenede Genel Prensipler}

Öykü alındıktan sonra, önce genel ortopedik muayene, ardından ayak muayenesi yapılır. Hekim yenidoğan döneminde "normal" olarak kabul edilen kas-iskelet sistemi özelliklerine aşina değilse ayağı değerlendirmesi zor olabilir. Normalde bebeklerde ayak arkı mevcut değildir, ancak bu dönemde yüksek ayak arkı nörolojik problemlerin bir göstergesi olabilir. Muayeneye başlarken çocuğa samimi ve nazik bir şekilde yaklaşmalıdır. Muayene her zaman istenen koşullarda olmayabilir. $\mathrm{Bu}$ şartları sağlamak hekimin tecrübesine de bağlıdır. Genel muayene, bağ laksitesini, alt ekstremitenin torsiyonel ve açısal varyasyonlarını ve yürüme şeklini değerlendirmeyi amaçlamalıdır. Başlangıçta, yürütülerek ya da bacaklarını hareket ettirmesi sağlanarak çocuğu izlemek mümkündür. Çocuğun etkilenmemesi için, daha odaya girerken, çocuk fark etmeden yürüyüşü gözlenebilir. Çocuk yürüme için işbirliği yapmazsa, odanın karşı tarafına taşınıp ebeveynine doğru yürümesi sağlanabilir. Hem ayakkabı ile hem de yalınayak yürütülmelidir. Ayakta ortaya çıkan dinamik sorunlar (dinamik ön ayak adduksiyonu gibi) yalın ayak yürürken gözlenebilir. Muayene sırasında yapılacak bazı manipülasyonların sırası çocuğun davranışlarına göre düzenlenerek, hoşlanmayacağı türde olanlar sona bırakılabilir. Genel olarak gözlem, palpasyon ve manipülasyonla muayene sürdürülür. Fonksiyonel ve biyomekanik değerlendirme için, hasta yürütüldükten sonra sıçrama ve sekme gibi bazı manevralar yaptırılabilir. Yürüme çağındaki çocuklarda alt ekstremite nörolojik değerlendirmesinde, parmak ucunda ayak bileği plantar fleksiyonda ve topuk üzerinde dorsifleksiyonda yürüme, tek bacak üstünde zıplama, hızlı ve duyarlı bir nörolojik muayene sağlar. Şüphe varlığında daha ayrıntılı muayene gerçekleştirilir.

Çocuk ayaktayken birçok durum değerlendirilebilir: pelvis yüksekliği, alt ekstremite dizilimi, arka ayak pozisyonu (varus-valgus), subtalar eklem pozisyonu (inversiyon-eversiyon), önayak pozisyonu (adduksiyon-abduksiyon), ayak arkı (kavuş-planus) ve parmakların durumu, bunun yanında şişlik ve kızarıklık gibi durumları gözlemek mümkündür. Çocuk sırtüstü ya da oturur pozisyonda iken de, alt ekstremite uzunluk ve dizilimi, arka ayak pozisyonu, ön ayak pozisyonu, değişen yük dağııımına bağlı ortaya çıkabilecek ayak tabanındaki nasırlaşmalar gözlenebilir.

Palpasyon ile ağrının yeri ön, orta veya arka ayağa ya da ayaktaki bazı eklemler üzerine lokalize edilebilir. Ağrı yerinin dikkatli tespiti özellikle travmatik olgularda tanıda oldukça yardımcıdır. Ayak ağrısının birçok nedeni tek taraflıdır; bu da etkilenmemiş tarafla karşılaştırma imkanı verir.

Ayak ilerleme açısı, ayağın ekseni ile ilerleme çizgisi arasındaki açı olup, içe doğru dönüklük negatif değerlerle ve dışa doğru dönüklük pozitif değerlerle ifade edilir. Normal yürüme açısı yaklaşık $10^{\circ}$ dışa doğrudur ve yedi yaşından sonra hafif bir azalma görülür. ${ }^{[1]}$ Bununla birlikte, negatif değerler, çocukluk ve erken yaşlar boyunca normal (iki standart sapma içinde ise) kabul edilir. ${ }^{[2]}$

\section{Sık Karşılaşılan Sorunlar}

Ayak deformiteleri yenidoğan döneminde nispeten yaygındır. Yenidoğanlarda yapılan bir çalışmada ayak deformitesi insidansı \%4,2 bulunmuştur. ${ }^{[3]}$ Bu anomalilerin yaklaşık dörtte üçünü metatarsus adduktus oluşturur; talipes equinovarus, kalkaneovalgus ve vertikal talus daha az görülen deformitelerdir.

Metatarsus adduktus çoğunlukla intrauterin pozisyonla ilişkilendirilir. Metatarsus adduktus deformitesinde ön ayak adduksiyondadır, ayak lateral kenarı eğimlidir ve topuk nötralde durur (fasulye şekli) (Şekil 1). Ayak aksiyel dizilimi yüz üstü pozisyonda da değerlendirilebilir. 


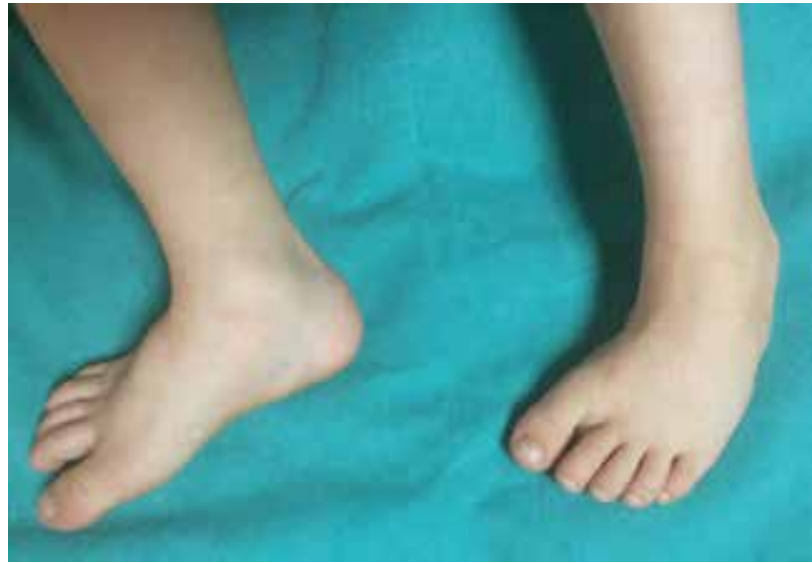

Şekil 1. Metatarsus adduktus. Ön ayak adduksiyondadır, ayak lateral kenarı eğimlidir ve topuk nötralde durur (fasulye şekli).

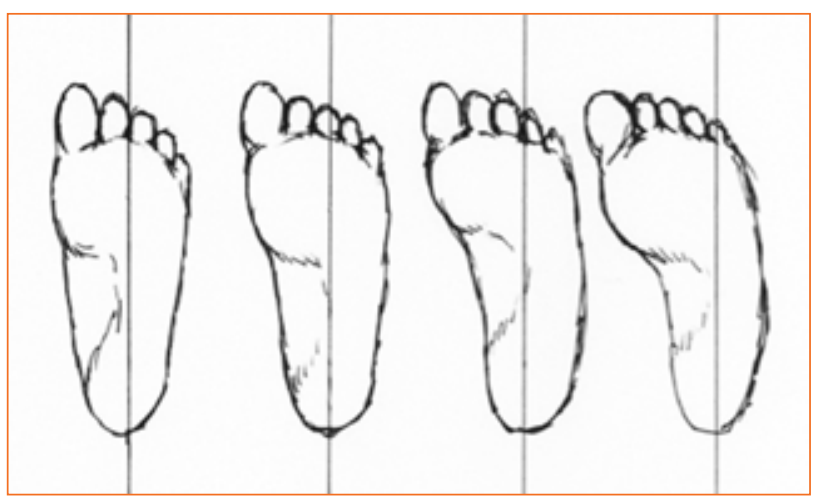

Şekil 2. Metatarsus adduktus deformitesinde klinik evreleme. Topuk orta hat çizgisi ile arka ve ön ayak ilişkisi belirlenir. (Bleck EE.'den ${ }^{[4]}$ yeniden çizilmiştir)

Klinik olarak Bleck ${ }^{[4]}$ tarafından tanımlandığı gibi, hafif, orta ve ciddi olarak ayrılabilir (Şekil 2). Topuk orta hat çizgisi, normal ayakta ikinci parmak arası boşluktan geçer. Bu çizgi ikinci parmak arası boşluğun lateralinden geçerse, ön ayak adduksiyonda demektir. Hat ikinci parmak arası boşluğun mediyalinden geçerse valgus olduğunu gösterir. Muayenede deformitenin esnek mi yoksa sert mi olduğunu değerlendirmek gerekir. Hafif deformitede ön ayak, ayak orta hattı ve ötesine abduksiyona getirilebilir. Orta derecedeki deformitede ise ön ayak orta hatta gelecek kadar esnektir. Sert deformitede ön ayak abduksiyon yapamaz. Abduktor hallusis kasındaki gerginliğin tespiti tanıda yardımcıdır. Bu amaçla Lichtblau testi yapılabilir. Bu testte, başparmak abduksiyona zorlanırken abduktor hallusis distalden proksimale doğru sıvazlanır, kasta kasılma veya üzerindeki deride beyazlama gerginlik belirtisidir. Esnek deformiteler gözlem ve germe egzersizleri ile izlenebilir. Sert deformitelerde ise, genellikle altı aydan önce

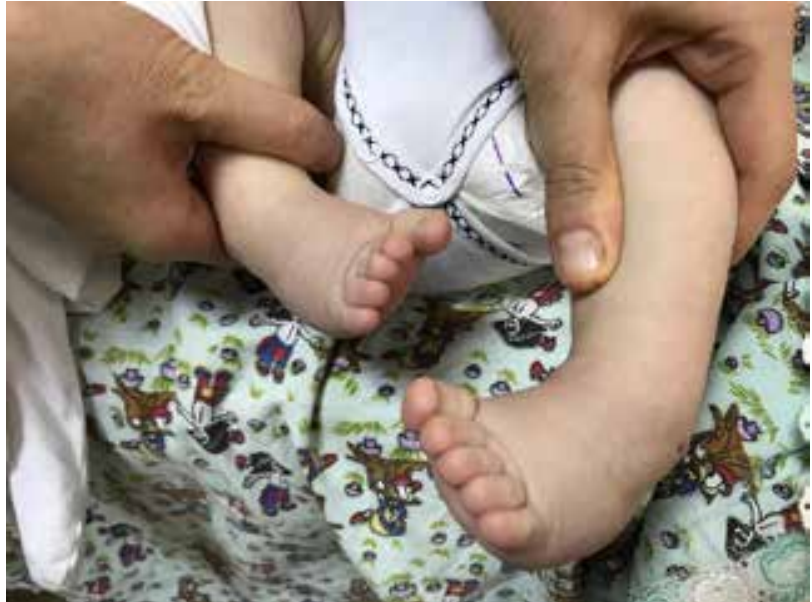

Şekil 3. İki taraflı çarpık ayakta klinik görünüm.

manipülasyon ve alçı tedavisi uygulanır. Metatarsus adduktusta cerrahi tedavi genellikle üç yaşından sonra planlanır ve nadiren gerekir. Metatarsus adduktuslu çocuklarda gelişimsel kalça displazisi insidansı normal popülasyona göre daha fazla olduğundan ${ }^{[5]}$, bu çocuklarda kalça eklemi dikkatle incelenmelidir.

Doğumsal ekin deformitesi izole olarak ortaya çıkabilse de daha çok çarpık ayak, konveks pes valgus veya fibular hemimelinin ekinovalgus bileşeni gibi daha karmaşık bir deformitenin parçası olarak görülür. Doğuştan çarpık ayak (pes ekinovarus) deformitesi ise, ayakta kavus, ön ayakta adduksiyon, arka ayakta varus ve ekin deformitesi ile karakterizedir (Şekil 3). Hafif postüral şekilden sert, ciddi deformiteye kadar çeşitli şekillerde ortaya çıkabilir. Ciddi pes ekinovarus deformitelerinin, artrogripozis, miyelomeningosel ve Larsen sendromu gibi patolojilerle birlikte olabileceği unutulmamalıdır. Fizik muayenede ayağın sertlik derecesi değerlendirilmeli, klinik evreleme yapılmalıdır. Eğer ayak tabanında derin bir çizgi varsa ve ayak sertse, konservatif tedaviye yeterli yanıt alınamayabilir. Klinik evrelemede ve tedavinin takibinde sık kullanılan Pirani deformite skorunu ${ }^{[6]}$ belirleyebilmek için, orta ayakta ayak dış kenarının büküklüğü, mediyal cilt kıvrımı ve talus başı örtülmesi; arka ayakta posterior cilt kıvrımı, ekin deformitesinin sertliği ve boş topuk değerlendirilir.

Kalkaneovalgus deformitesinin hafif formları yenidoğan döneminde sıkça görülür. Bu çocuklarda arka ayak dış rotasyonda ve dorsifleksiyonda durur. Bu nedenle, bazı hastalarda ayak sırtı tibia önü ile temas halinde olabilir. Belirgin bir kalkaneovalgus görüntüsü ile ortaya çıkan tibianın posteromediyal bowing deformitesi ayağın kalkaneovalgus deformitesi ile karışabilir. Kalkaneovalgusta deformitenin tepesi ayak bileğinde 


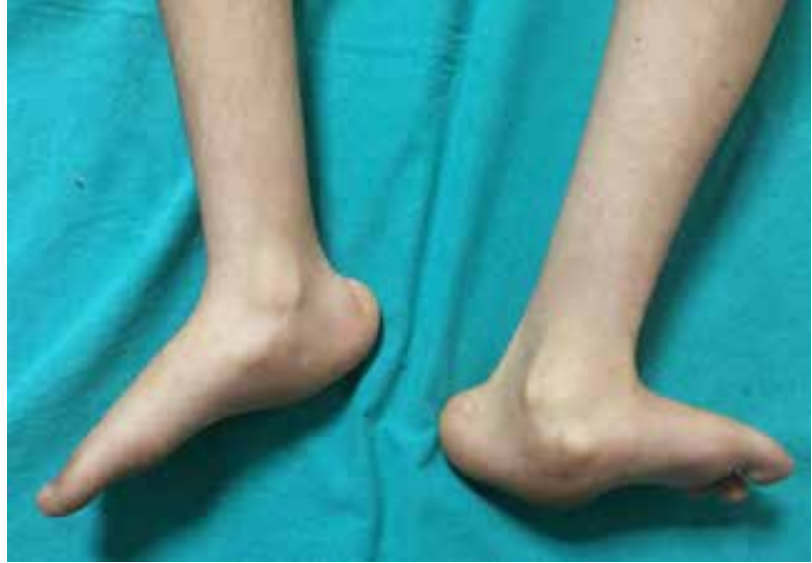

Şekil 4. Karakteristik 'rocker-bottom' deformitesi ile konjenital vertikal talusun klinik görünümü.

iken, tibianın posteromediyal eğiminde deformitenin tepesi distal tibiadadır. Kalkaneovalgus olgularında germe tedavileri yarar sağlasa da birçok deformite 3-6 ayda tedavi edilsin ya da edilmesin kendiliğinden iyileşir. Tibianın posteomediyal eğim deformitesinde ise ekstremite eşitsizliği (genellikle 3-4 cm) ortaya çıkabilir.

Konjenital vertikal talus seyrek görülen bir ayak deformitesidir; kalkaneovalgus ayakla karışabilir. Konjenital vertikal talus, arka ayağın ekin pozisyonunda olması ile karakterizedir; ön ayak ise dorsifleksiyondadır (Şekil 4). Bu durum, talonaviküler eklemden orta ayağın çıkığı sonucu meydana gelir. Esnek olan kalkaneovalgus ayağın aksine, konjenital vertikal talus, konveks plantar yüz ile sert bir deformitedir; 'rocker-bottom' deformitesi görünümü meydana gelir. Konjenital vertikal talus sıklıkla artrogripozis veya miyelodisplazi ile birlikte olduğundan, hasta bu patolojiler açısından da değerlendirilmeli ve genetik konsültasyon yapılmalıdır. ${ }^{[7]}$

Düztabanlık (pes planovalgus) çocuklarda sık hastaneye başvuru nedenlerindendir. Düztabanlık esnek, kısa Aşil tendonu ile birlikte esnek ve peroneal spastik-sert olabilir. Düztabanlı çocuklarda ayağın esnekliği, subtalar eklem hareketliliği ile ilgilidir. Düztabanlık, subtalar kompleksin aşırı eversiyonu ile karakterizedir. Mediyal kolona göre ayağın lateral kolonu kısadır. Lateral talokalkaneal açı artmış olsa da, talus ve kalkaneus her ikisi de tibiaya göre plantar fleksiyondadır. Esnek düztabanlıkta, ayağa yük verilmediğinde mediyal uzun ayak arkı oluşur, ancak yük verme sırasında ark çöker (Şekil 5). Büyük çocuk ve adolesanlarda sıklıkla tarsal koalisyonla birlikte tespit edilen sert düztabanlık ise seyrek görülür, yük verilmediğinde de ark çökmüş haldedir ve elle düzeltilemez. Düztabanlığın esnek ya da sert olduğunu ayırt etmek için çocuk ayak parmakları üzerinde

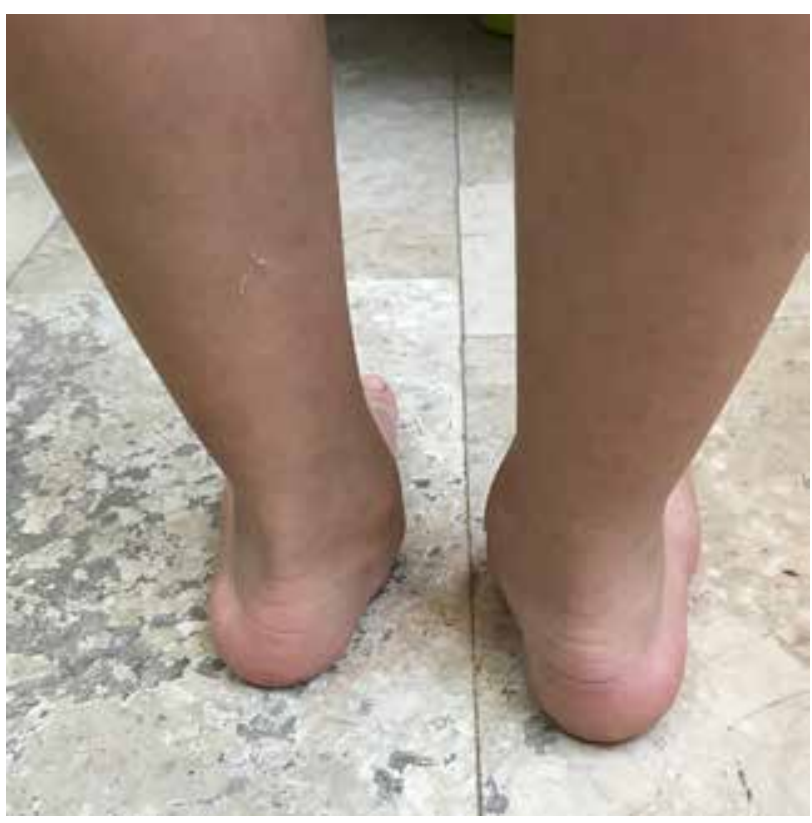

Şekil 5. Her iki ayakta valgus deformitesinin arkadan görünümü.

yükseltilebilir ya da Jack testi yapılabilir. ${ }^{[8]}$ Esnek düztabanlı çocuklarda arka ayak, parmak ucunda yükselme sırasında ve Jack ayak direnci testiyle valgustan varusa düzelir ve kemer yükselir. Bu iki manevrada da, plantar fasyanın 'windlass' hareketi ile subtalar eklem inversiyona gider ve uzunlamasına bir kemer oluşur. Jack testinde ayak başparmağı, ayakta iken elle dorsifleksiyona zorlanır. Mediyal uzunlamasına kemer başparmağın dorsifleksiyonundan dolayı yükselirse, ayak esnek olarak kabul edilir (Şekil 6). Mediyal uzunlamasına kemer değişmezse, ayak serttir. Esnek düztabanlıkla birlikte, arka ayakta valgus dizilimi, talusun mediyal ve plantara eğimi, ön ayağın arka ayağa göre göreceli supinasyonu görülür. Birçok çocukta ayak arkı yüksekliği normal büyüme boyunca ve ilk on yılda artar. Esnek düztabanlı çocuklar, zorlu egzersiz sonrası veya günün sonunda zaman zaman bacak veya ayak ağrısı hissetseler de nadiren semptomatiktirler. Kısa Aşil tendonlu veya tarsal koalisyonlu çocuk veya adolesanların ise $\% 25$ 'i sinus tarsi bölgesine, arka ayağın mediyal kenarına veya talus başı altına lokalize ağrıdan yakınırlar. Çocuk yüzükoyun pozisyonda yatarken, dizi hiperfleksiyona getirdikten sonra ayak bileği dorsifleksiyona alınıp ayak bileğinin etkisi azaltılarak subtalar eklem hareketlerini değerlendirmek mümkündür. Çocuk topuğuna basarak yürüyebiliyorsa Aşil tendonunun kısa olmadığı düşünülebilir.

Gerçek ayak bileği dorsifleksiyonu ve Aşil tendonu gerginliğinin değerlendirmesi de önemlidir. Ayak bileği ekleminde talus hareketini izole etmek ve değerlendirmek 


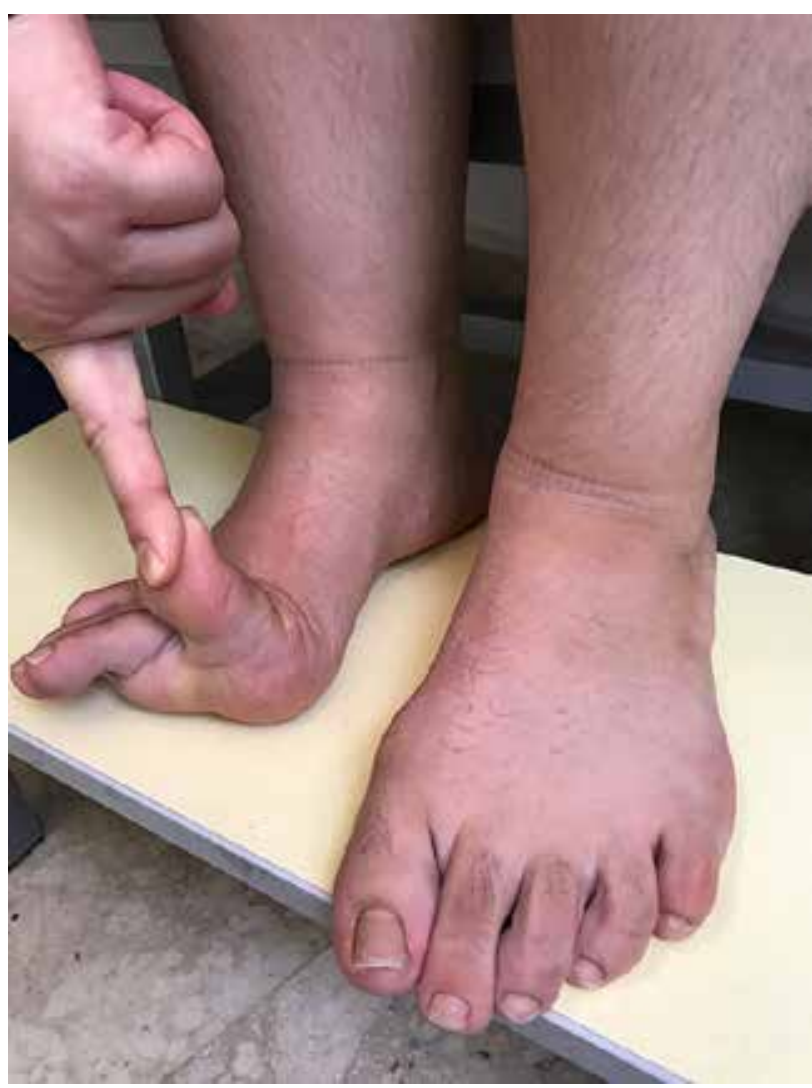

Şekil 6. Esnek düztabanlıkta sağ ayakta birinci parmağın elevasyonu ile uzunlamasına ayak arkının oluşması (Jack testi).

için, subtalar eklem kompleksi nötral duruma getirilmeli ve bu pozisyonda kilitli tutulmalıdır. Dorsifleksiyon, ayağın plantar-lateral sınırı ile ön tibia şaftı arasındaki açı olarak ölçülür; $10^{\circ}$ 'den daha az dorsifleksiyon, Aşil tendonunun kontraktürünü gösterir. Sonra, subtalar eklem nötralde tutulurken ve ayak bileği ekleminin dorsifleksiyonunu sürdürmeye çalışırken diz uzatılır; dorsifleksiyon tekrar ölçülür. Diz fleksiyonda iken, $10^{\circ}$ 'den fazla ayak bileği dorsifleksiyonu mümkün fakat diz ekstansiyonda iken $10^{\circ}$ 'den daha az ise, bu durum tek başına gastroknemius kısalığını gösterir.

Tarsal koalisyonu olan birçok çocuk tamamen asemptomatik kalabilse de, geç çocukluk döneminde ve ergenlik çağında bar kemikleşip arka ayak sertleşince semptomatik hale gelebilir. Bu durum, kalkaneonaviküler koalisyon için 8-12 yaş ve talokalkaneal koalisyon için 12-16 yaş arasında ortaya çıkar. Hastalar, özellikle ayağın dorsolateral bölgesinde sinus tarsi alanında ağrıdan ve hafif ayak yorgunluğundan şikayetçidirler. Düzgün olmayan yüzeylerde yürümekte güçlük çekebilirler. Sportif aktivitelerden sonra ağrı, topallama ya da spor sırasında sık ayak bileği burkulması öyküsü olabilir. Tarsal koalisyonlu hastalarda yürüme normal görünebilir. Bununla birlikte, belirsiz ağrı yürümesi veya yürüme sırasında dışa ayak ilerlemesi de gözlemlenebilir. Çocukta, genellikle ayak arkında düzleşme vardır ve çocuk ayak parmakları üzerinde yukarı kalktığında tam olarak düzelmez. Arka taraftan bakıldığında, hasta ayak parmağı üzerinde yükselirken, topuk esnek düztabanlıkta olduğu gibi hafif valgustan varusa doğru dönmeyebilir. Tarsal hareketi kısıtlı olan hastalarda, ayağın supinasyonu ile ortaya çıkan, tibianın tipik dışa rotasyonu da sınırlı olacaktır. Bu hastalarda, peroneal spazm olsun veya olmasın, azalmış veya ağrilı subtalar hareket klasik bir bulgudur. Ayak bileği, tekrarlayan burkulmalara ikincil aşırı gevşeklik gösterebilir. Palpasyonla duyarlılık; sinus tarside, kalkaneonaviküler barlarda dorsolateral bölgede ve talokalkaneal barlarda posteromediyal bölgede görülebilir. Nadiren, ayağın tabanında duyu bozukluğu tespit edildiğinde, talokalkaneal barın tibial siniri veya kalkaneal sinir dallarını sıkıştırmasına bağlı ortaya çıkabilen tarsal tünel sendromu akla gelmelidir.

Kavus deformitesi, ayağın anormal derecede yüksek uzun arka sahip olmasıdır. Bu durum, ön ayağın plantar fleksiyon ya da kalkaneusun dorsifleksiyon deformitesine bağlı olabilir. Çoğu kavus ayağı hastasında fizik muayene, duyusal bozuklukların, motor zayıflı̆ı̆n, atrofinin ve derin tendon reflekslerinin incelendiği kapsamlı bir nörolojik değerlendirme içermelidir. Buna ek olarak tüm hastalarda, sakral çukur, kıllı deri veya hemanjiyom varlığı gibi altta yatan omurilik patolojisi bulguları araştırılmalıdır.

Kavus ayakta, ayağın fizik muayenesi ilk olarak kavus deformitesinin bileşenlerini belirlemeye odaklanmalıdır. Fizik muayenede; ayak bileği, arka ayak, ön ayak ve ayak parmaklarını ayrı ayrı değerlendirmek pratik olabilir. Muayenede, ayağı hem ağırlık taşıyan hem de taşımayan pozisyonda değerlendirmek gereklidir. Arka ayağın pozisyonu (varus veya valgus) hasta ayakta iken incelenebilir. Aşil tendonu gergin olsa bile, pes kavuslu hastalarda gerçek ayak bileği ve arka ayak ekinusu nadirdir. Ayağın ekin görüntüsü, genellikle ön ayağın ekin duruşundan kaynaklanır ve kalkaneus, ön ayağın plantar fleksiyonuna yanıt olarak dorsifleksiyondadır.

Kavus deformitesi, genellikle arka ayağın varus deformitesi ile birlikte görülür. Bir tedavi planı yaparken, arka ayak varusunun sert veya esnek olup olmadığını belirlemek önemlidir. Esnek arka ayak varusuna genellikle birinci sıranın plantar fleksiyonu neden olur. Arka ayağın esnekliği sıklıkla Coleman blok testi ile belirlenir. ${ }^{[9]}$ Coleman blok testinde, hasta topuk veya ön ayağın lateral kenarının altında bir blok üzerinde dururken, birinci ile üçüncü metatars başlarının mediyalden bloktan düşmesine izin verilir. Arka ayak gövdesi esnekse ve birinci metatarsın plantar fleksiyonuna ikincil 


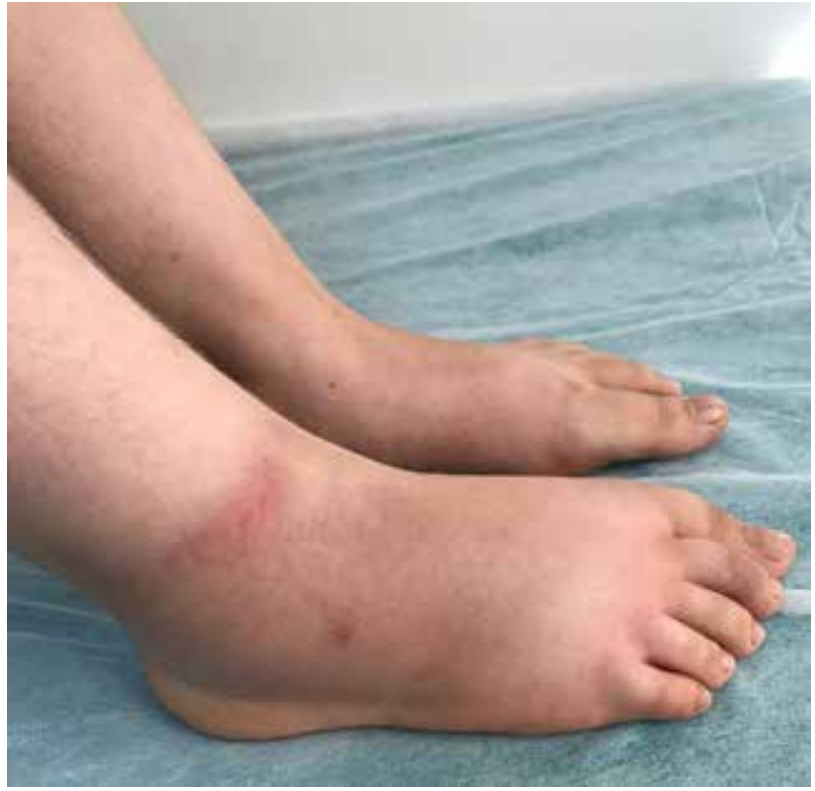

Şekil 7. Sağ ayakta travma sonrası meydana gelen ödem. Bu hastada, ağıının tam lokalizasyonu tanıda oldukça yardımcı olabilir.

ise, topuk bu testle birlikte nötral veya valgus duruşu gösterecektir. Eğer Coleman blok testi sırasında arka ayak varusu değişmezse deformite serttir. Arka ayağın esnekliği, hasta yüz üstü yatarken diz $90^{\circ}$ fleksiyonda iken de değerlendirilebilir. Ön ayağın ekin deformitesinin yanı sıra plantar fasya gerginliğine de bakılmalıdır. Bazı hastalarda öncelikle birinci metatars plantar fleksiyonu bulunurken, diğerlerinde tüm metatarslar ekinde olabilir. Ön ayak ekininin esnekliği ve ciddiyeti değerlendirilmelidir. Ayak parmakları, pençeleşme ve herhangi bir metatarsofalangeal veya interfalangeal eklem deformitesinin esnekliği açısından muayene edilmelidir. Tek taraflı kavus deformitesi görülen olgularda medulla spinalis patolojisi, iki taraflı olanlarda ise kalıtsal nöropatiler araştırılmalıdır.

Özellikle yürüme çağında travma nedeniyle başvuran çocuklarda dikkatli muayene ve ağrı yerinin tespiti tanıya oldukça yardımcıdır. Ağrı ile birlikte genellikle şişlik mevcuttur (Şekil 7). Dikkatli yapılan bir muayene sonu$\mathrm{cu}$, radyografi gerekliliği ve hangi radyografinin isteneceği daha doğru tespit edilebilir.

\section{SONUÇ}

Çocuklarda ayak yakınmaları hastaneye sık başvurma nedenidir. Yenidoğan döneminde genellikle doğumsal deformiteler görülürken, yürüme çağından itibaren travma ve buna bağlı ağrı yakınmaları öne geçer. Özellikle yeni yürüyen çocukta, ayaktaki aileyi kaygılandıran sorunların nereye kadar fizyolojik, nereden sonra patolojik olduğunu belirlemek her zaman kolay olmayabilir. Çocuğun başvuru nedenini dikkatle dinlemek çoğu zaman tanıda yol göstericidir. Öykü alındıktan sonra, gözlem, palpasyon ve manipülasyon ile sürdürülen muayene, basit tetkiklerle birlikte çoğu zaman tanıda yeterli olur.

\section{Teşekkür}

Fotoğrafların temininde katkı sağlayan Dr. Oğuz Türker ve Dr. Naci Ruşen Senih Ayan'a teşekkür ederim.

\section{KAYNAKLAR}

1. Engel GM, Staheli LT. The natural history of torsion and other factors influencing gait in childhood. A study of the angle of gait, tibial torsion, knee angle, hip rotation, and development of the arch in normal children. Clin Orthop Relat Res 1974;99:12-7.

2. Staheli LT, Corbett M, Wyss C, King H. Lower-extremity rotational problems in children. Normal values to guide management. J Bone Joint Surg Am 1985;67(1):39-47.

3. Widhe $T$. Foot deformities at birth: a longitudinal prospective study over a 16-year period. J Pediatr Orthop 1997;17(1):20-4

4. Bleck EE. Metatarsus adductus: classification and relationship to outcomes of treatment. J Pediatr Orthop 1983;3(1):2-9.

5. Kumar SJ, MacEwen GD. The incidence of hip dysplasia with metatarsus adductus. Clin Orthop Relat Res 1982;(164):234-5.

6. Flynn JM, Donohoe M, Mackenzie WG. An independent assessment of two clubfoot-classification systems. J Pediatr Orthop 1998;18(3):323-7.

7. Hoffinger SA. Evaluation and management of pediatric foot deformities. Pediatr Clin North Am 1996;43(5):1091-111.

8. Jack EA. Naviculo-cuneiform fusion in the treatment of flat foot. J Bone Joint Surg Br 1953;35-B(1):75-82.

9. Coleman SS, Chesnut WJ. A simple test for hindfoot flexibility in the cavovarus foot. Clin Orthop Relat Res 1977;(123): $60-2$. 